\title{
Suomi NPP VIIRS DNB and RSB M bands detector-to-detector and HAM side calibration differences assessment using a homogenous ground target
}

\author{
Xuexia Chen*1, Ning Lei ${ }^{1}$, Xiaoxiong Xiong ${ }^{2}$ \\ ${ }^{1}$ Science Systems and Applications Inc., Lanham, Maryland, 20706 \\ ${ }^{2}$ NASA Goddard Space Flight Center, Greenbelt, Maryland, 20661
}

\begin{abstract}
Near-nadir observations of the Libya 4 site from the S-NPP VIIRS Day-Night Band (DNB) and Moderate resolution Bands ( $M$ bands) are used to assess the detector calibration stability and half-angle mirror (HAM) side differences. Almost seven years of Sensor Data Records products are extracted from the Libya 4 site center over an area of $32 \times 32$ pixels. The mean values of the radiance from individual detectors per HAM side are computed separately. The comparison of the normalized radiance between detectors indicates that the detector calibration differences are wavelength dependent and the differences have been slowly increasing with time for short wavelength bands, especially for M1-M4. The maximum annual average differences between DNB detectors are $0.77 \%$ in 2017 at HAM-A. For the M bands, the maximum detector differences in 2017 are $1.7 \%$ for $\mathrm{M} 1,1.8 \%$ for $\mathrm{M} 2,1.3 \%$ for $\mathrm{M} 3,1.2 \%$ for $\mathrm{M} 4,0.67 \%$ for $\mathrm{M} 5,0.75 \%$ for $\mathrm{M} 7,0.57 \%$ for $\mathrm{M} 8,13 \%$ for $\mathrm{M} 9,0.63 \%$ for $\mathrm{M} 10$, and $0.66 \%$ for $\mathrm{M} 11$. The average HAM side A to B difference in 2017 are $0.00 \%$ for DNB, $0.22 \%$ for M1, $0.17 \%$ for M2, $0.15 \%$ for M3, $0.09 \%$ for M4, $-0.07 \%$ for M5, $0.02 \%$ for $\mathrm{M} 7,0.01 \%$ for $\mathrm{M} 8,1.4 \%$ for $\mathrm{M} 9,0.01 \%$ for $\mathrm{M} 10$, and $0.03 \%$ for M11. Results for M6 are not available due to the signal saturation and M9 results are not accurate because of the low reflectance from the desert site and the strong atmospheric absorption in this channel. The results in this study help scientists better understand each detector's performance and HAM side characteristics. Additionally, they provide evidence and motivation for future VIIRS calibration improvements.
\end{abstract}

Keywords: S-NPP VIIRS, Day-Night band, Moderate resolution bands, detector calibration difference, HAM, Libya 4

\section{INTRODUCTION}

\subsection{S-NPP VIIRS Sensor Overview}

The Suomi National Polar-orbiting Partnership (S-NPP), launched on October 28, 2011, is one of the modern Earthobserving weather satellites. It makes a bridge to provide continuity between NASA's Earth Observing System (EOS) Satellites and the Joint Polar Satellite System satellites to observe Earth elements, including the land, ocean, and atmosphere [1, 2, 3]. The five instruments onboard S-NPP are the Visible Infrared Imaging Radiometer Suite (VIIRS), the Cross-Track Infrared Sounder, the Ozone Mapping and Profiler Suite, the Advanced Technology Microwave Sounder, and the Cloud and Earth Radiance Energy System. VIIRS data has been used to measure cloud and aerosol properties, ocean color, ocean and land surface temperatures, ice movement and temperature, fires, and Earth's albedo.

VIIRS is designed based on MODIS heritage, and is a wide-swath $(3034 \mathrm{~km})$, cross-track scanning radiometer which collects data of the Earth's surface in 22 visible and infrared spectral bands (400-12500 nm). Among the 22 spectral bands, there are 15 Reflective Solar Bands (RSB) and 7 Thermal Emissive Bands (TEB). The VIIRS instrument was powered on November 08, 2011 and the instrument nadir door was opened on November 21, 2011. Since then the VIIRS has been collecting observation data for more than 6 years.

Among the RSB, the DNB on VIIRS is a visible/near-infrared panchromatic band, which can observe the Earth during both daytime and nighttime. The spatial resolution of the DNB is $750 \mathrm{~m}$ and there are 32 aggregation zones through each half of the instrument swath on either side of nadir. In order to provide imagery of clouds and Earth targets from full sunlight to quarter moon illumination status, the DNB comprises three gain stages: the low gain stage (LGS), the

*xuexia.chen@ssaihq.com; phone 1301 867-2047 
medium gain stage (MGS), and the high gain stage (HGS). The LGS is used for observing bright Earth scenes at day time, the MGS is used for scenes near the terminator or at twilight, and the HGS is used for night scenes. In this study the data that we used focus on the DNB LGS.

The VIIRS M1-M7 bands are used primarily for ocean color and aerosol applications; the M8, M9, M11, M14, I4, and I5 bands are used for clouds; M12, M13, M15 and M16 are primarily used for sea surface temperature; I3 and M10 are used for snow; and I2 and I1 are used for Normalized Difference Vegetation Index (NDVI) and imagery. The following table 1 has listed the VIIRS sensor spectral bands characteristics.

Table 1. List of characteristics of VIIRS Sensor DNB, I bands, and M bands.

\begin{tabular}{|c|c|c|c|c|c|}
\hline $\begin{array}{l}\text { VIIRS } \\
\text { Band }\end{array}$ & $\begin{array}{l}\text { Wavelength } \\
\text { Range (nm) }\end{array}$ & Primary Earth Data Records & Gain Stages & $\begin{array}{c}\text { Band } \\
\text { Explanation }\end{array}$ & $\begin{array}{c}\text { Spatial } \\
\text { Resolution } \\
\text { at Nadir (m) }\end{array}$ \\
\hline M1 & $402-422$ & Ocean Color Aerosols & Low, High & \multirow{5}{*}{ Visible/Reflective } & \multirow{16}{*}{$750 \mathrm{~m}$} \\
\hline M2 & 436-454 & Ocean Color Aerosols & Low, High & & \\
\hline M3 & $478-488$ & Ocean Color Aerosols & Low, High & & \\
\hline M4 & $545-565$ & Ocean Color Aerosols & Low, High & & \\
\hline M5 & $662-682$ & Ocean Color Aerosols & Low, High & & \\
\hline M6 & $739-754$ & Atmospheric Correction & Single & \multirow{2}{*}{ Near IR } & \\
\hline M7 & $846-885$ & Ocean Color Aerosols & Low, High & & \\
\hline M8 & $1230-1250$ & Cloud Particle Size & Single & \multirow{4}{*}{ Shortwave IR } & \\
\hline M9 & $1371-1386$ & Cirrus Cloud Cover & Single & & \\
\hline M10 & $1580-1640$ & Snow Fraction & Single & & \\
\hline M11 & $2230-2280$ & Clouds & Single & & \\
\hline M12 & $3610-3790$ & Sea Surface Temperature & Single & \multirow[b]{2}{*}{ Medium-wave IR } & \\
\hline M13 & $3970-4130$ & $\begin{array}{c}\text { Sea Surface } \\
\text { Temperature/Fires }\end{array}$ & Low, High & & \\
\hline M14 & $8400-8700$ & Cloud Top Properties & Single & \multirow{3}{*}{ Longwave IR } & \\
\hline M15 & $10260-11260$ & Sea Surface Temperature & Single & & \\
\hline M16 & $11540-12490$ & Sea Surface Temperature & Single & & \\
\hline DNB & $500-900$ & Day/Night Band & $\begin{array}{c}\text { Low, Middle, } \\
\text { High } \\
\end{array}$ & Visible/Reflective & $\begin{array}{c}750 \mathrm{~m} \\
\text { across full scan }\end{array}$ \\
\hline I1 & $600-680$ & Imagery Band & Single & Visible/Reflective & \multirow{5}{*}{$375 \mathrm{~m}$} \\
\hline $\mathrm{I} 2$ & $850-880$ & NDVI & Single & Near IR & \\
\hline $\mathrm{I} 3$ & $1580-1640$ & Binary Snow Map & Single & Shortwave IR & \\
\hline $\mathrm{I} 4$ & $3550-3930$ & Imagery Band Clouds & Single & Medium-wave IR & \\
\hline $\mathrm{I} 5$ & $10500-12400$ & Imagery Band Clouds & Single & Longwave IR & \\
\hline
\end{tabular}

VIIRS DNB and each M band have 16 detectors; and each I band has 32 detectors in the along-track direction. VIIRS M bands and I bands detectors are distributed on three Focal Plane Assemblies (FPAs) [4]. These M bands and I bands detectors are rectangular in shape with the smaller dimension in the along scan direction with considerations made for the different pixel growth rates in both scan and track directions. The VIIRS sensor observation altitude is $828 \mathrm{~km}$. The Rotating Telescope Assembly (RTA) scans the Earth between scan angles $\pm 56.28^{\circ}$ off nadir. At scan angles greater than approximately $19^{\circ}$, the bow-tie effect leads to scan-to-scan overlap [5]. These overlap pixels are assigned fill values and their radiometric readings are not transmitted to the ground. These data gaps showed in raw data will not display when the data is projected or gridded based on the Earth's surface. The DNB detectors design are more complicated than the M bands and I bands detectors. DNB detectors are a backside-illuminated Charge-Coupled Device (CCD) detector chip 
which has three different gains through four separated stages relative to different light-sensitiveness [4]. DNB sub-pixel aggregation is performed in both the scan and track direction, thus the DNB has $750 \mathrm{~m}$ resolution across full scan. For all VIIRS spectral bands, the best signal to noise ratios are in the nadir view of the scan.

\subsection{S-NPP VIIRS RSR}

The Relative Spectral Responses (RSR) of all VIIRS bands were well measured and provided by the government team in the pre-launch test programs [6,7]. Figure 1 indicates pre-launch RSR of all VIIRS RSB bands and their comparison with normalized solar power. Shortly after S-NPP launch, several VIIRS reflective solar bands had decreased optical throughput due to the mirror coating contamination of the RTA [1,8], which also caused RSRs to change over time. Modulated band averaged RSRs are generated at different times during SNPP mission, and are used to update postlaunch SDRs Look-Up-Table (LUT) to correct the RTA mirror contamination effect $[9,10]$.

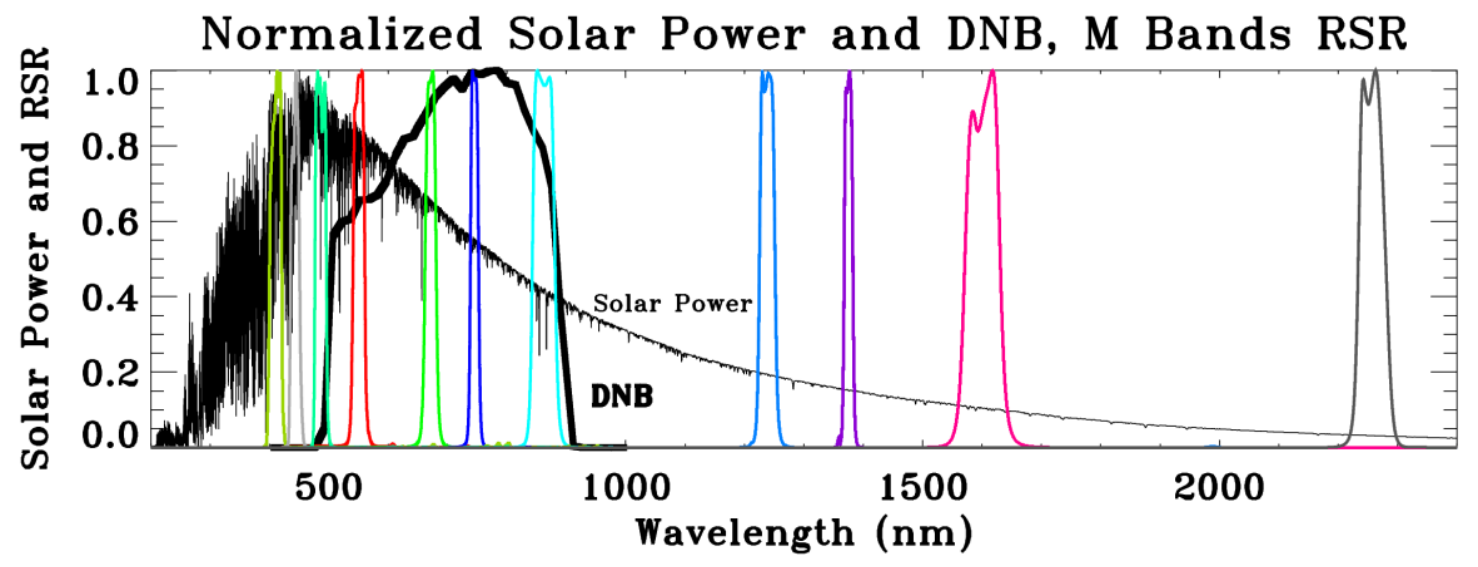

M8 M9 M10

M11

Figure 1. DNB and M bands pre-launch RSRs, and normalized solar power.

\subsection{Previous Study on Detector Difference}

The simplest imaging sensor only carried a single detector. It only scanned a series of lines or narrow strips across the targets [11]. In contrast to this type of conventional imaging radiometer, most current imaging sensors, such as MODIS and VIIRS, contain several FPAs with multiple detectors aligned in the along-track direction. A single scan from these sensors can collect multiple cross-track strips recorded by aligned detectors, so that an image scene can be finished fast and the scan rate is slower than that of a single detector imaging sensor [12]. This slower scan rate design can increase the dwell time for each pixel which leads to higher signal-to-noise ratio (SNR). The disadvantage of this multi-detector arrangement design is the overlapped pixel toward the swath edges and imagery striping due to detector differences [12].

Many methodologies have been investigated on studying detector difference of imaging sensors. A ratio approach was applied to co-located MODIS and MISR pixels to study Terra collection 5 detector-to-detector difference and mirror side difference [13]. The Terra detector-to-detector differences were believed to be caused by systematic calibration bias from the use of the solar diffusor (SD). Ground targets, including Dark Oceanic site near Equator Pacific Ocean area and the desert site Libya 4 in the Sahara Desert were also used for MODIS collection 6 data detector difference study [14, 15]. Recent research in 2016 used the Deep Convective Cloud (DCC) measurements to assess the difference among MODIS detectors [16]. The DCC research found that Terra MODIS Collection 6 detector differences were less than $1 \%$ for bands $1,3-5$, and 18 . The differences were up to $2 \%$ for bands 6,19 , and 26 and the largest difference was $4 \%$ for band 7. For Aqua bands, most detector differences were less than $0.5 \%$ except bands 19 and 26 , which were up to $1.5 \%$.

Scientists have also studied the detector differences and HAM side differences in S-NPP VIIRS products. Stripe noise was found in some level 1 data, including the M12, M15 and M16 bands [17, 18]. They believed these striping EV data were influenced by the detector RSR difference, the atmospheric influence, digital count restoration (DCR), and detector 
instability [17, 18]. Many correction models were tested to reduce the striping, including a unidirectional quadratic variational model [17] and Line-by-Line radiative transfer model [18]. Wang et al. [18] found that the noise along track direction was the major reason for the striping observed in VIIRS M15 and M16 imagery. D1 and D2 in M15, and D9 and D12 in M16 had much higher noise levels than other detectors in the same band. Another DCC research study on SNPP VIIRS indicates that most solar reflective bands' detector differences were less than $1 \%$ to the average value, except for I3 and M10 bands [19]. The HAM side difference of S-NPP VIIRS was insignificant and stable with time. Recent research by Lei et al. 2017 [20] investigated the reflectance of the SD panel changes over time and found that the SD bidirectional reflectance distribution function (BRDF) value degraded with time. The degradation factor was both incident sunlight and outgoing direction dependent [20]. It was believed that the SD BRDF was one of the sources for the detector differences in S-NPP VIIRS.

\subsection{Objective of This Study}

Previous studies on VIIRS ocean color products [21] indicated that the ocean color Environmental Data Record (EDR) products are highly sensitive to the Sensor Data Record (SDR) data quality. Improving the calibration F-LUT in the VIIRS Raw Data Record (RDR) to SDR data processing can increase accuracy in the EDR products. Approximately $0.1 \%$ accuracy in SDR data is required to derive good quality ocean color EDR products [22]. Thus, it is very important to assess and monitor the S-NPP VIIRS products quality. The main objective in this research is using the ground target, Libya 4, to monitor the VIIRS DNB and RSB M bands detector-to-detector differences and HAM side differences from 2012 February to 2018 June. We make efforts to find the possible root causes of striping and the amount of difference change with time, and we also compare our results with some previous studies to better understand the performance of the VIIRS instrument.

\section{STUDY SITE, DATA, AND METHODOLOGY}

\subsection{Study Site}

Several Earth surface sites with stable radiometric characteristics are widely used as references to monitor satellite sensor long-term stability $[14,15,23]$. Libya 4 is one of the test sites that are endorsed by the Committee on Earth Observation Satellites (CEOS) Working Group on Calibration and Validation (WGCV) as being "reference standards" (http://calval.cr.usgs.gov/sites_catalog_ceos_sites.php).

The Libya 4 desert site [Lat. $28.55^{\circ}$, Lon. $23.39^{\circ}$ ] is close to horizontally uniform and is a relatively homogeneous area covered by sands in Africa [24, 25]. The Libya 4 site is often selected as a calibration study site based on its high spatial uniformity and temporally invariant surface cover properties for stable reflectance and BRDF [23-26]. This site is located in arid regions and thus has a low probability of cloudy weather and precipitation. Also this site contain high reflectance in most visible and near infrared bands and it is "bright" on the Earth, thereby it has a high signal-to-noise ratio (SNR) in the Earth view observation data. Figure 2 shows Libya 4 site observed from the 2018 Landsat image data. The SCIAMACHY spectra of Liby4 site are provided by the European Space Agency. We integrated the spectral resolution to better display this site's reflectance characteristics. Figure 3 indicates that the reflectance of the Libya 4 site is high in visible and near infrared and there is some atmospheric influence for wavelengths larger than $1000 \mathrm{~nm}$. 


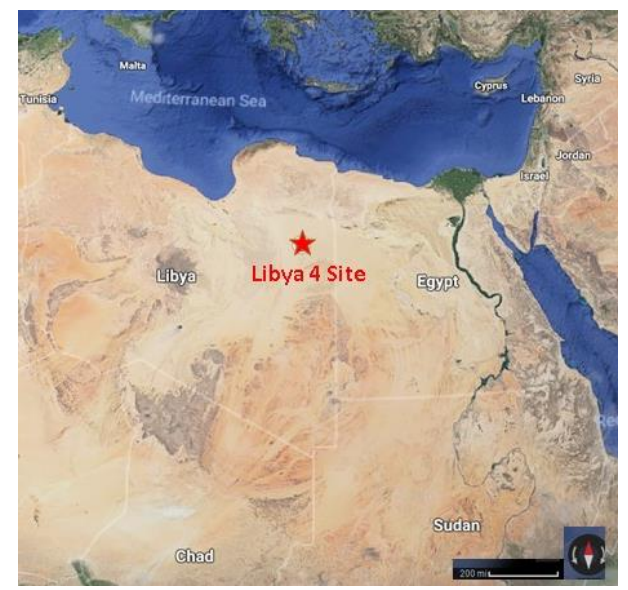

Figure 2. Google map of Libya 4 site based on 2018 Landsat images.

Libya4 SCIAMACHY Spectra

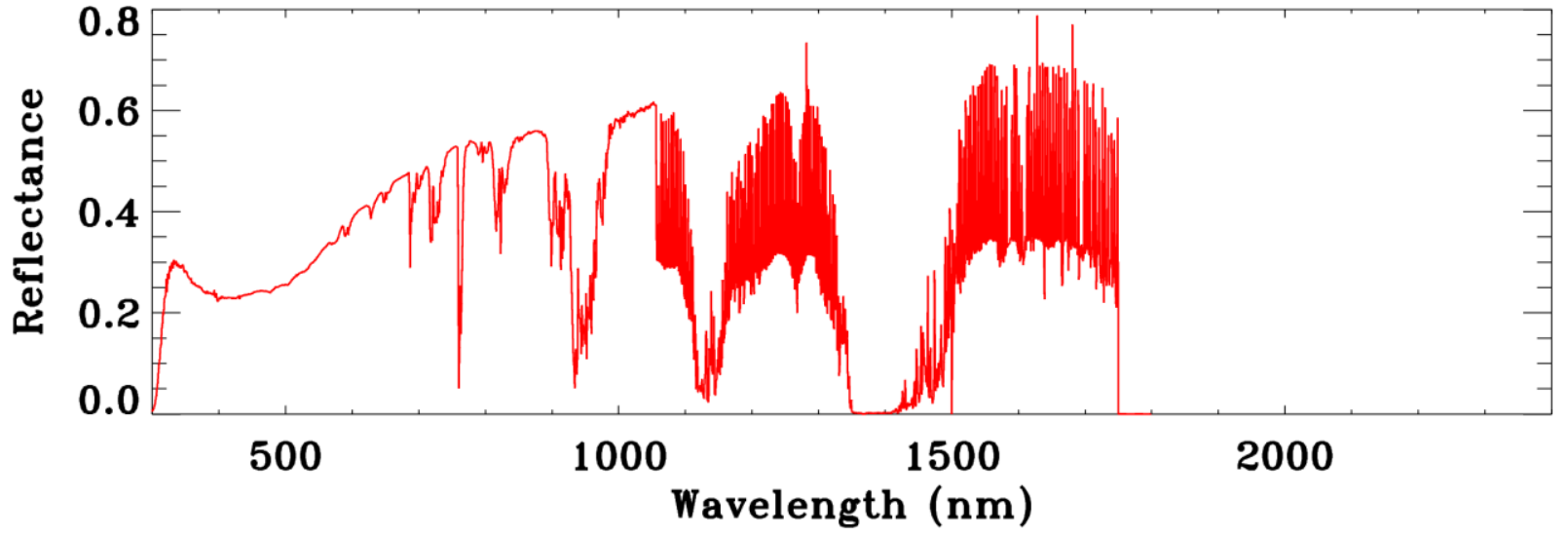

Figure 3. SCIAMACHY spectra of Libya 4.

\subsection{Data Selection}

The data products used in this study are the NASA S-NPP VIIRS L1B data at nadir on Libya 4 site which can be downloaded from Level 1 and Atmosphere Archive and Distribution System (LAADS) (https://ladsweb.modaps.eosdis.nasa.gov/). We used the products made at VIIRS Land SIPS (Science Investigator Processing System) 5000-LSIPS C1 Processing. This version of LSIPS data has been reprocessed with improved calibration algorithms and LUTs [https://landweb.modaps.eosdis.nasa.gov/NPP_QA/]. Three products were downloaded including DNB, M-bands, and On-board Calibrator Intermediate Products (OBC IPs). We selected the data near nadir overpass for Libya 4 to cover the period between S-NPP launch and June 2018. In this study, the solar irradiance LUT is provided from Aerospace Corporation and the modulated RSR LUTs are provided by the VIIRS Characterization Support Team (VCST). Among the data we used, the on orbit screen transmittance functions were generated from yaw maneuver data and regular on-orbit data conducted early in the mission and the RSR functions have been updated several times and were implemented in data processing [10].

Images are examined both by calculating standard deviation values of the Libya 4 site radiance and by visual investigation. We exclude the data that show less homogeneity, where the $32 \times 32$ pixels derived from DNB coefficient of variation $(\mathrm{CV})$ is higher than 0.03 and $\mathrm{M}$ bands $\mathrm{CV}$ are higher than 0.02 , except $\mathrm{M} 9$. For M9, we used the 0.2 as $\mathrm{CV}$ filter since the variation is larger in this band due to the atmospheric influence and low surface reflectance. Thus any images with clouds, shadows, or inhomogeneous surface structure over Libya 4 site were excluded for this study. 
In addition, the distances from study site center pixel ([Lat. $28.55^{\circ}$, Lon. $\left.23.39^{\circ}\right]$ ) to nadir are less than 60 DNB pixels, which is within $45 \mathrm{~km}$ on ground distance, and the satellite zenith angles are less than 3.5 degrees. The solar zenith angle range is from 14 to 55 degrees for Libya 4 . We extract 32 by 32 pixels to calculate the DNB and M-bands mean radiance per detector per HAM side. The extracted DNB pixels are all within the aggregation zone 1 thus each DNB detector signal studied in this paper is integrated from certain subpixel detectors from the CCD detector chip. All observations are at daytime thus the DNB data are all observed in low gain stage at the Libya 4 site. At the Libya 4 site, M1 and M2 bands are in high gain stage; M3 band has both high gain and low gain stage observation due to different seasons; and M4, M5, and M7 bands are all in low gain stage. Based on the above requirements, Libya 4 site images are selected from 16-day repeatable orbits so all data have approximately the same viewing geometry relative to the site.

\subsection{Detector and HAM-side Difference Calculation}

DNB SDRs include calibrated and geolocated radiance data, while the $M$ bands SDRs contain both radiance and reflectance data. $\mathrm{L}_{\mathrm{m}}$ is provided by the DNB SDRs product directly, which is calibrated considering the response versus scan angle (RVS) of the HAM and the SD BRDF degradation using the time dependent modulated RSR [1, 8, 10]. The DNB radiance with the Earth-Sun distance and solar zenith angle normalization are calculated for each pixel using the following equations (1)-(2).

$$
L_{\text {normalized }}=\frac{L_{m} * d^{2}}{\cos (\theta)}
$$

$L_{\text {normalized }}=$ Measured solar radiance after Earth-Sun distance and solar zenith angle normalization $\left(\mathrm{W} \cdot \mathrm{cm}^{-2} \cdot \mathrm{Sr}^{-1}\right)$

$L_{m}=$ Measured solar radiance imported from the SDR DNB product $\left(\mathrm{W} \cdot \mathrm{cm}^{-2} \cdot \mathrm{Sr}^{-1}\right)$

$d$ =Earth-Sun distance (astronomical units)

$\theta=$ Solar zenith angle (degree)

We used OBC IPs data to extract HAM side and detector information for each pixel and do the statistics analysis based on the HAM side and detector classification. Then we use equation (2) to calculate the normalized radiance for each detector based on the ratio of individual detector value to the mean values of all detectors per HAM side.

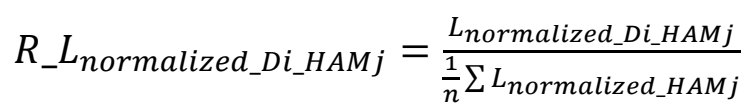

$R \_L_{n o r m a l i z e d} D i_{-} H A M j=$ Normalized ratio of detector i HAM side $\mathrm{j}$ radiance.

$L_{\text {normalized_Di_HAMj }}=$ Measured solar radiance of detector i HAM side $\mathrm{j}$ after Earth-Sun distance and solar zenith angle normalization (equation 1).

$\frac{1}{n} \sum L_{n o r m l i z e d \_H A M j}=$ Mean value of $L_{\text {normalized }}$ for all detectors in HAM j. $\mathrm{n}$ is the total number of detectors.

The M bands radiance $\left({ }^{L_{m_{-} \text {Mband }}}\right)$ and normalized radiance $\left({ }_{\text {normalized_Mband }}\right)$ data are calculated using the scaled integer (SI), scale, and offset values provided by the SDR products following equations (3) - (4).

$$
\begin{aligned}
& L_{m_{-} \text {Mband }}=S I * \text { scale }+ \text { offset } \\
& L_{\text {normalized_Mband }}=\frac{L_{m_{-} \text {Mband }} * d^{2}}{\cos (\theta)}
\end{aligned}
$$

The calculation of the M-bands normalized ratio for detector i HAM side $\mathrm{j}$ radiance is similar to the DNB method in equation (2). The HAM side ratio is also calculated based on the radiance ratio of each detector for the two HAM sides (equation 5). Later, simple yearly averages of the detector differences and HAM side ratios are calculated for each detector to remove the seasonal variation influence. 


$$
H A M_{-} \text {Ratio }_{D i}=\frac{L_{\text {normalized }} \text { Di_HamA }_{\text {Hormalized }}}{L_{\text {Di_HamB }}}
$$

\subsection{Image Striping}

\section{RESULTS}

For a multi-detector imaging sensor, if the instrument was characterized perfectly and the measurements from each detector and each mirror side are accurate after calibration, then there would be no striping in the image product. Striping is a consequence of the calibration algorithm, where each detector is calibrated independently but there are differences in the radiance measurement from each detector and each mirror side due to the calibration inaccuracy. It is hard to characterize the instrument perfectly because of limited time and cost. As a result, striping artifacts are very common in image products. In this study, we found that the DNB and M1-M4 bands have some striping artifacts that are visible by eye [figure 4]. These striping artifacts could be introduced by several factors such as the two-side scan mirror not being characterized perfectly, the detector responses changing with time due to RSR change, or the detectors may be noisy. To assess the striping in VIIRS, we have investigated the detector difference and HAM side difference in long term trending. The results are presented in sections 3.2 and 3.3.
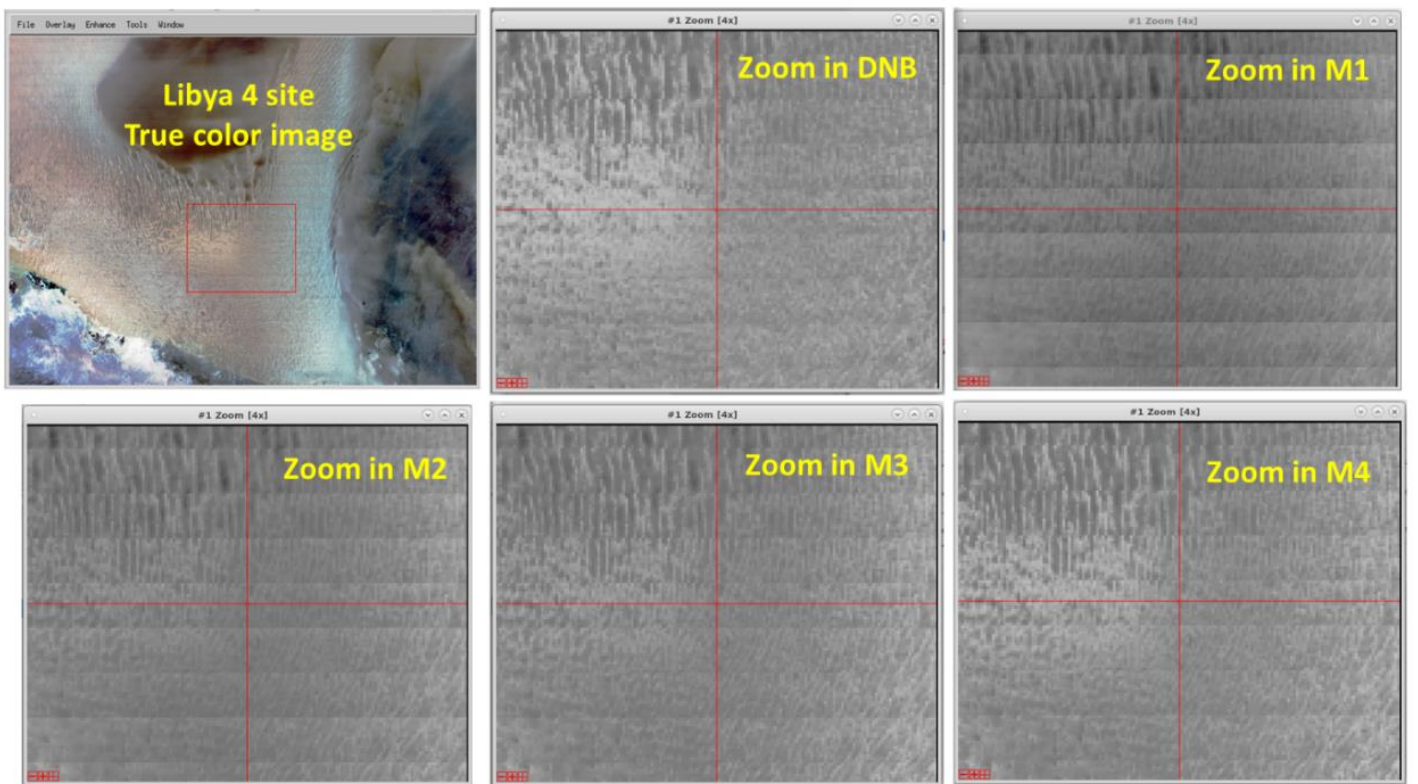

Figure 4. S-NPP true color image (M5/R, M4/G, M3/B), and zoom in images for DNB and M1-M4 bands on 2018/178. All images are radiance products with enhanced effect by a Gaussian stretch in ENVI software.

\subsection{Libya 4 Site Radiance Trends for Detector Differences}

For the Libya 4 site, the detector radiance has strong seasonal oscillations due to the solar zenith angle and Earth-Sun distance changes [figure 5]. The normalization of these two factors has significantly removed the seasonal variation [figure 6]. To better understand the difference between detectors, we calculate the ratio of individual detector's radiance to the mean radiance of all detectors per HAM side [figure 7]. After averaging the sampled data for each year, from 2012 to 2018 , the plot [figure 8] indicates detector difference information based on the above statistical method. 


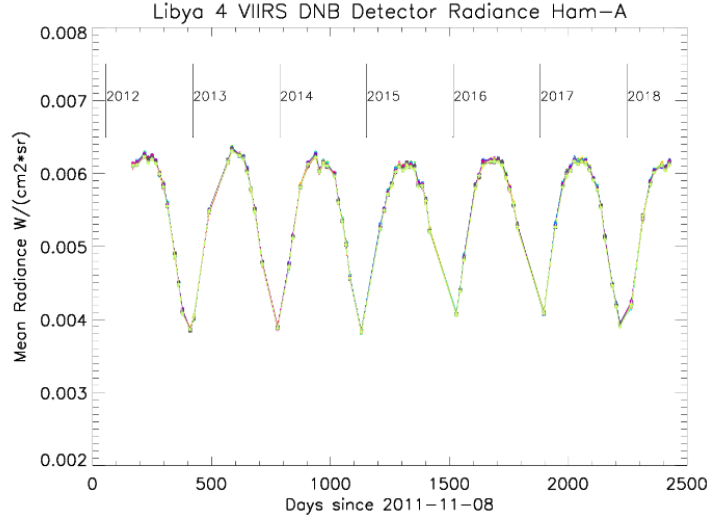

Figure 5. Libya 4 site DNB radiance trending for each detector at HAM A.

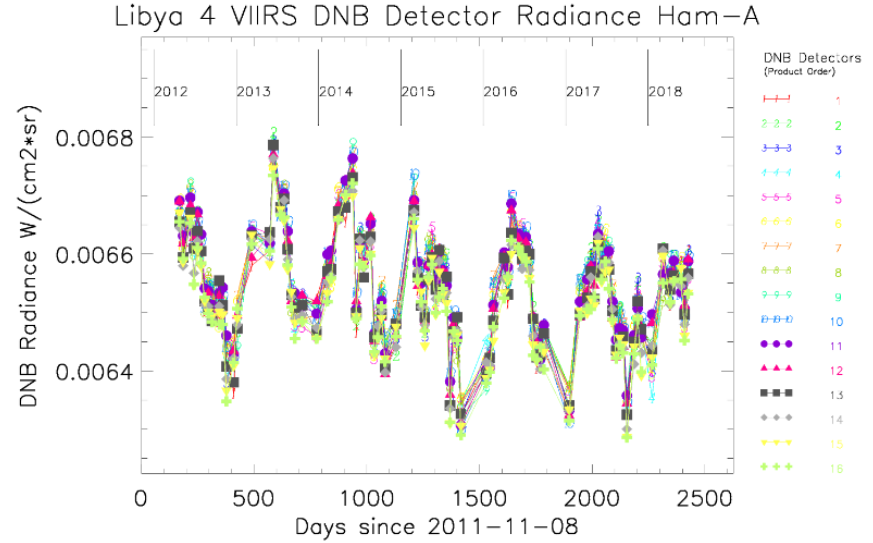

Figure 6. Libya 4 site DNB solar zenith angle and Earth-Sun distance normalized radiance trending at HAM A.
VIIRS DNB Detector Radiance Normalized to Mean Ham-A

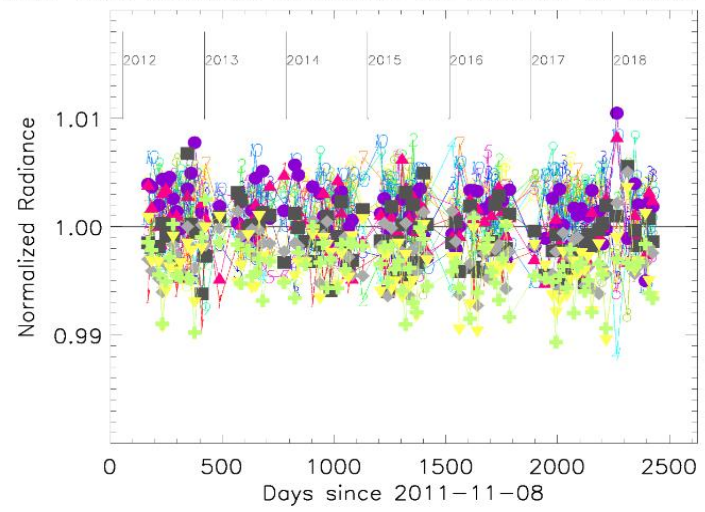

Figure 7. Libya 4 site DNB radiance ratio of individual detector to the mean at HAM-A.
Libya 4 VIIRS DNB (Ham-A) Radiance Normalized to Mean

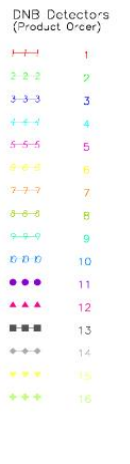
.

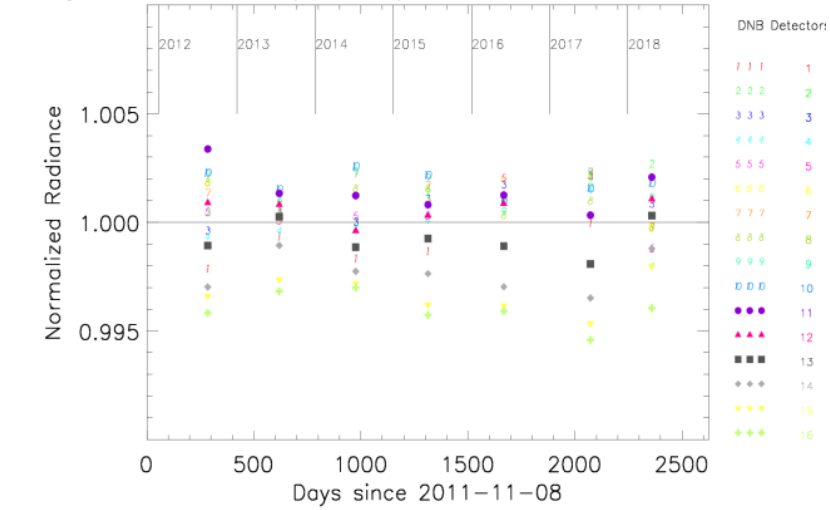

Figure 8. Libya 4 site DNB yearly average radiance ratio of individual detector to the mean at HAM-A.

For DNB, there is a general decline in the trending as the detector number increases, which indicates a possible small calibration bias [figure 9]. The variations between adjacent detectors are very small, most of them are within $0.2 \%$, so the difference between one scan line to the next is small unless that is the edge detectors, D1 and D16. This result matches the striping observations in the DNB radiance image in figure 4. The DNB maximum detector difference is $0.77 \%$ in 2017 HAM-A side [figure 9 and table 2]. There is also a general increase in the value of maximum detector difference from 2012 to 2017 yearly average data. 
Libya 4 L1B DNB Detector Difference Ham-A

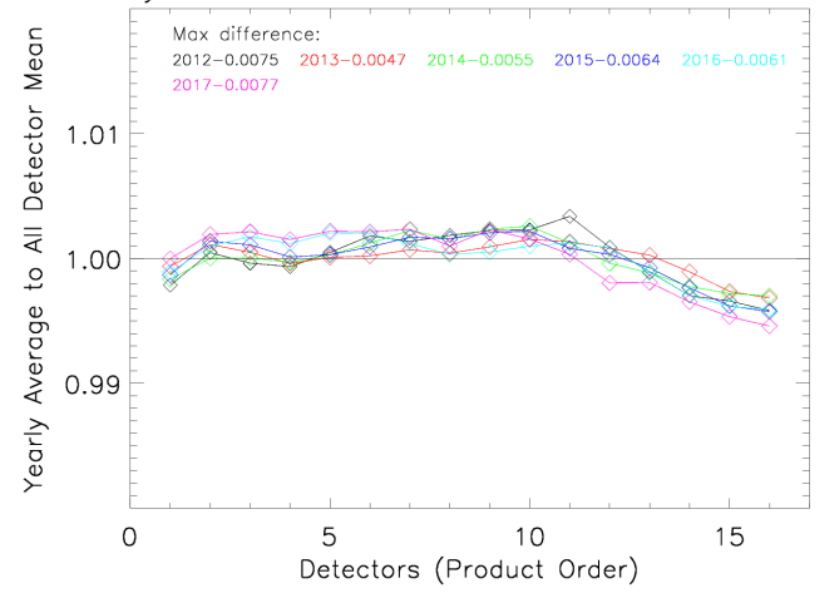

Libya 4 L1B DNB Detector Difference Ham-B

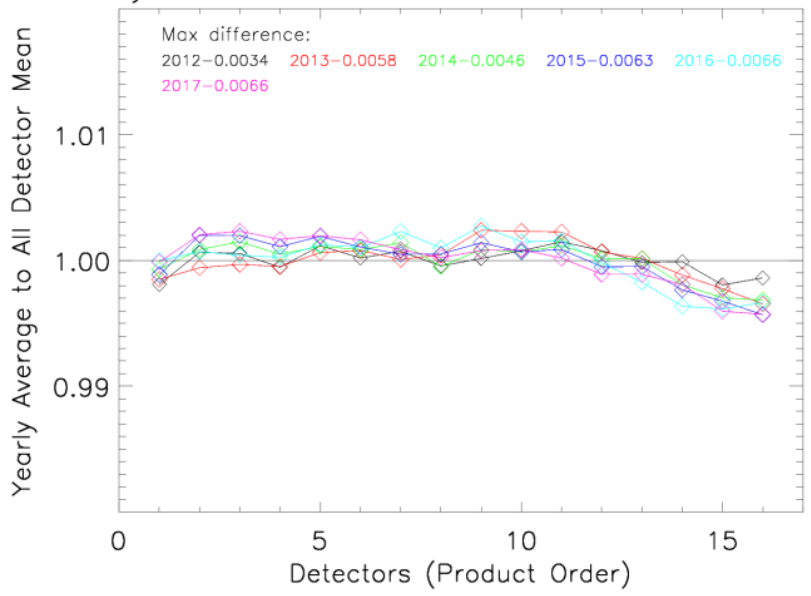

Figure 9. Libya 4 site DNB per full year average radiance ratio of individual detector to the mean at two HAM sites.

Figure 10 shows the RSB M bands detectors differences. These results indicate that the detector difference is dependent on the band wavelength. The shorter wavelength bands show larger relative detector differences (M1- M4). This is consistent with the wavelength-dependent SD degradation found in S-NPP. There is more degradation in shorter wavelength bands than in the longer wavelength bands [20]. There is no available data for M6 due to the signal saturation at the Libya 4 site. The M9 reflectance is low and the sensor detected signals become extremely small and the results are less stable comparing with other RSB due to its low SNR. In 2017, M1-M4 maximum detector differences are higher than 1\% [table 2] and there is a general increase of the maximum detector difference in the trending as the time increases since launch. The M1-M4 striping can be observed from the images of radiance [figure 4]. For the RSB M bands, the maximum detector differences in 2017 are $1.7 \%$ for $\mathrm{M} 1,1.8 \%$ for $\mathrm{M} 2,1.3 \%$ for $\mathrm{M} 3,1.2 \%$ for $\mathrm{M} 4,0.67 \%$ for $\mathrm{M} 5,0.75 \%$ for $\mathrm{M} 7,0.57 \%$ for M8, $13 \%$ for $\mathrm{M} 9,0.63 \%$ for M10, and $0.66 \%$ for M11. In addition, we have investigated each detector's radiance standard deviation values, and average them for each year. We do not find any detectors that are noisy or have significantly higher standard deviation than other detectors.
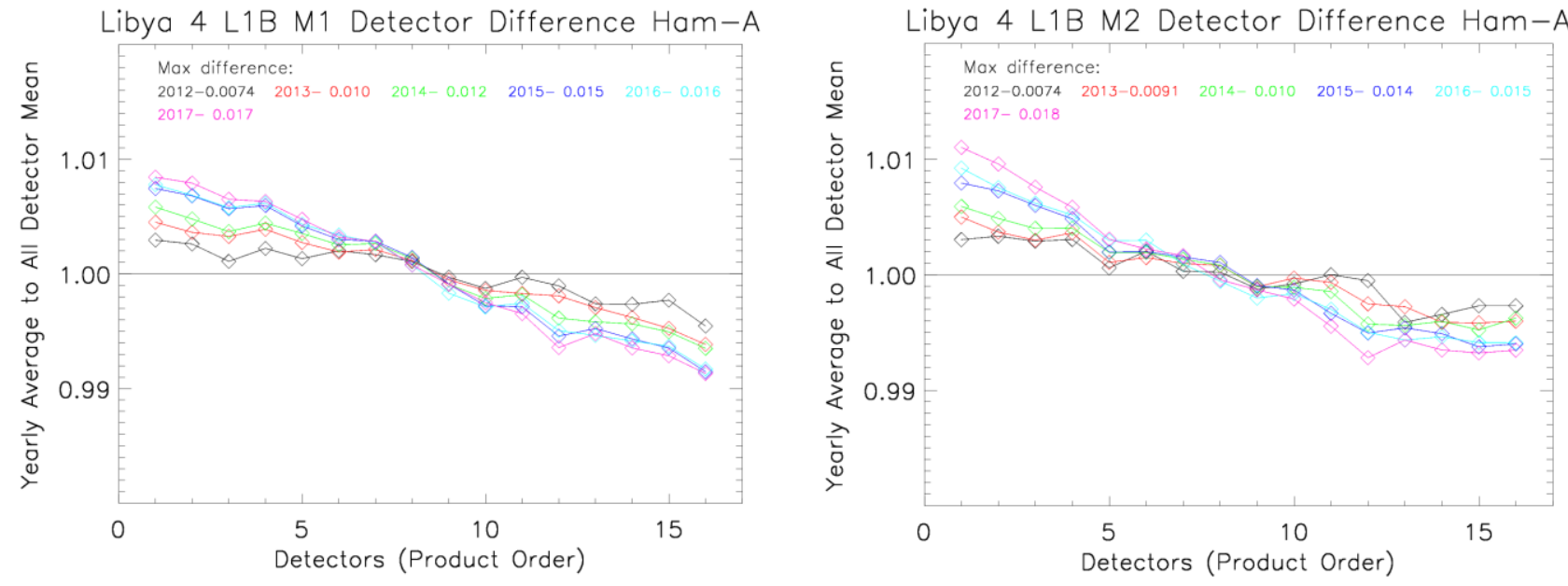
Libya 4 L1B M3 Detector Difference Ham-A

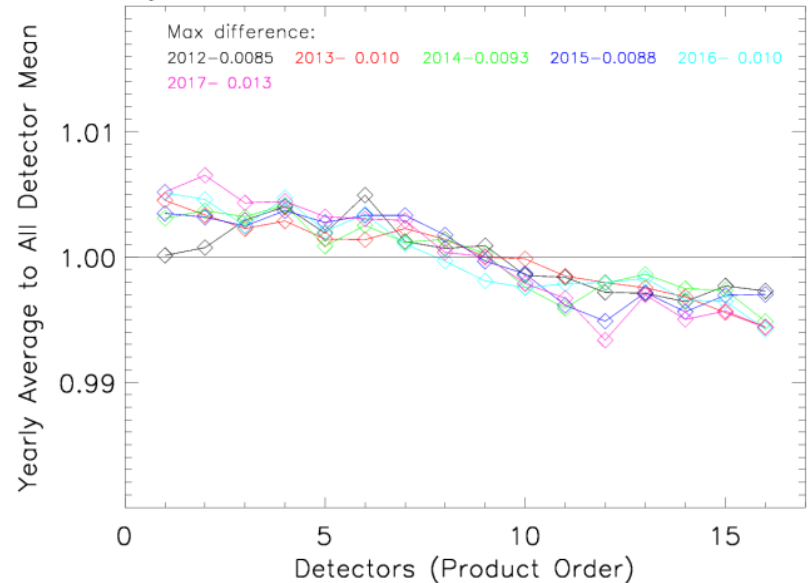

Libya 4 L1B M5 Detector Difference Ham-A

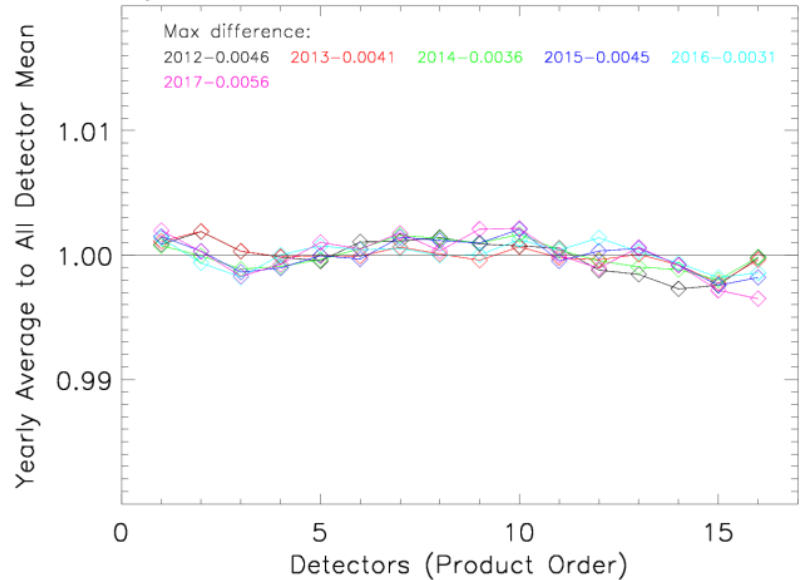

Libya 4 L1B M8 Detector Difference Ham-A

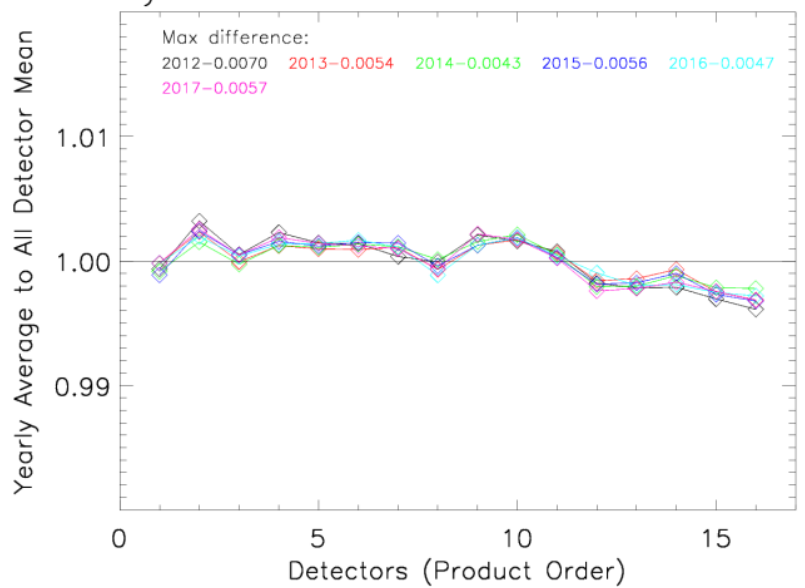

Libya 4 L1B M4 Detector Difference Ham-A

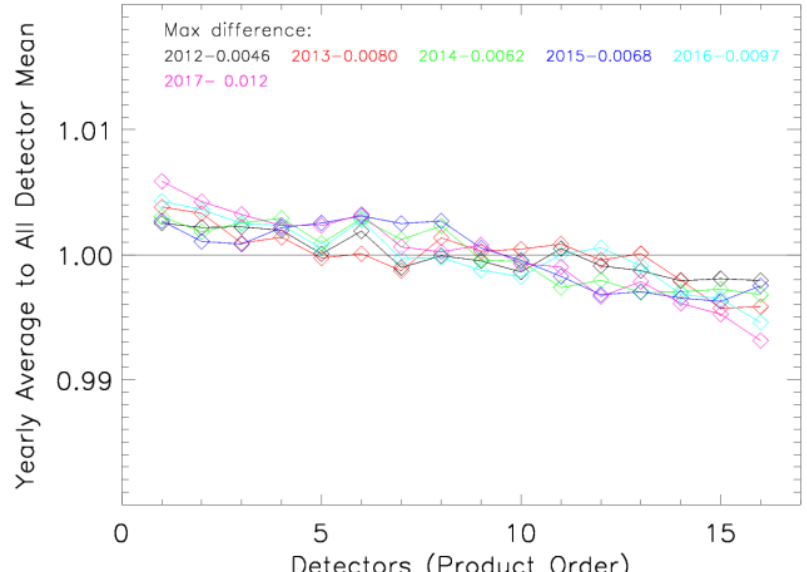

Libya 4 L1B M7 Detector Difference Ham-A

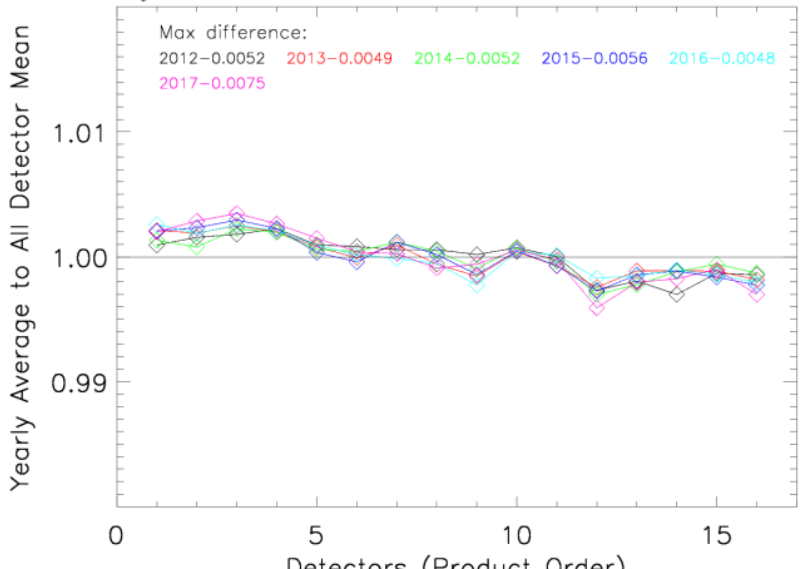

Libya 4 L1B M9 Detector Difference Ham-A

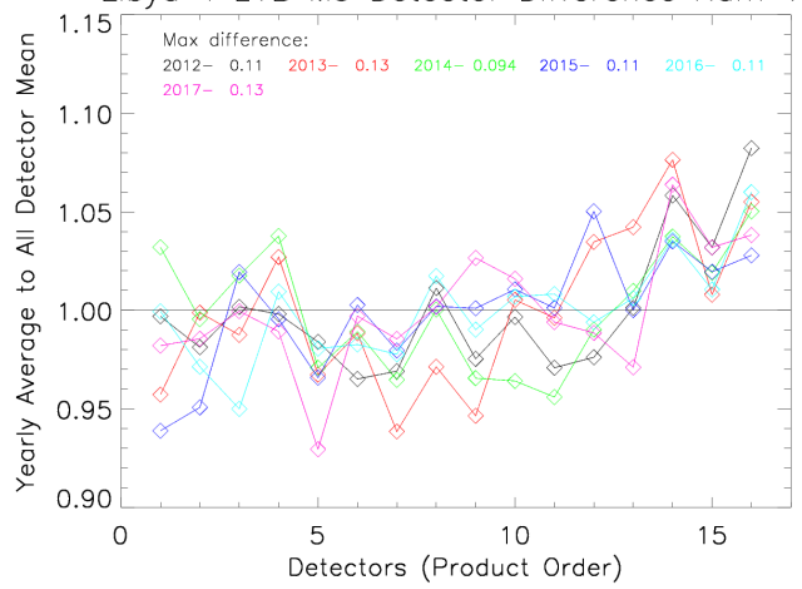



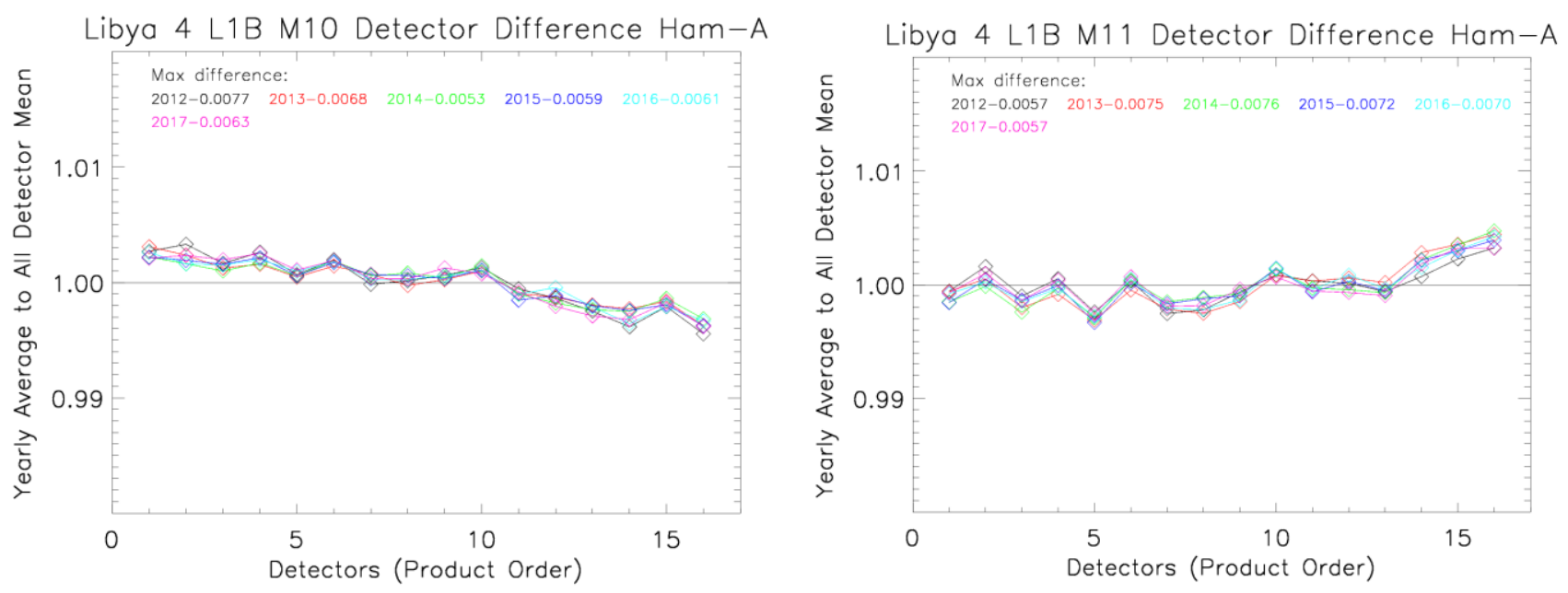

Figure 10. Libya 4 M1-M5, M7-M11 yearly average radiance of individual detector to all detectors' mean at HAM-A.

Table 2. List of maximum detector difference in yearly averaged data. The numbers highlighted in yellow are larger than 0.01 .

\begin{tabular}{|c|c|c|c|c|c|c|c|c|}
\hline \multirow{2}{*}{ Band } & \multirow{2}{*}{$\begin{array}{c}\text { Center } \\
\text { Wavelength }(\mathrm{nm})\end{array}$} & \multirow{2}{*}{ HAM } & \multicolumn{6}{|c|}{ Year } \\
\hline & & & 2012 & 2013 & 2014 & 2015 & 2016 & 2017 \\
\hline \multirow{2}{*}{ DNB } & \multirow{2}{*}{700} & Ham-A & 0.0075 & 0.0047 & 0.0055 & 0.0064 & 0.0061 & 0.0077 \\
\hline & & Ham-B & 0.0034 & 0.0058 & 0.0046 & 0.0063 & 0.0066 & 0.0066 \\
\hline \multirow{2}{*}{ M1 } & \multirow{2}{*}{412} & Ham-A & 0.0074 & 0.0100 & 0.0120 & 0.0150 & 0.0160 & 0.0170 \\
\hline & & Ham-B & 0.0077 & 0.0098 & 0.0140 & 0.0160 & 0.0160 & 0.0170 \\
\hline \multirow{2}{*}{ M2 } & \multirow{2}{*}{445} & Ham-A & 0.0074 & 0.0091 & 0.0100 & 0.0140 & 0.0150 & 0.0180 \\
\hline & & Ham-B & 0.0073 & 0.0073 & 0.0120 & 0.0140 & 0.0160 & 0.0180 \\
\hline \multirow{2}{*}{ M3 } & \multirow{2}{*}{448} & Ham-A & 0.0085 & 0.0100 & 0.0093 & 0.0088 & 0.0100 & 0.0130 \\
\hline & & Ham-B & 0.0075 & 0.0071 & 0.0095 & 0.0120 & 0.0110 & 0.0130 \\
\hline \multirow{2}{*}{ M4 } & \multirow{2}{*}{555} & Ham-A & 0.0046 & 0.0080 & 0.0062 & 0.0068 & 0.0097 & 0.0120 \\
\hline & & Ham-B & 0.0048 & 0.0069 & 0.0084 & 0.0100 & 0.0099 & 0.0120 \\
\hline \multirow{2}{*}{ M5 } & \multirow{2}{*}{672} & Ham-A & 0.0046 & 0.0041 & 0.0036 & 0.0045 & 0.0031 & 0.0056 \\
\hline & & Ham-B & 0.0038 & 0.0045 & 0.0044 & 0.0057 & 0.0058 & 0.0067 \\
\hline \multirow{2}{*}{ M7 } & \multirow{2}{*}{865} & Ham-A & 0.0052 & 0.0049 & 0.0052 & 0.0056 & 0.0048 & 0.0075 \\
\hline & & Ham-B & 0.0046 & 0.0043 & 0.0062 & 0.0056 & 0.0055 & 0.0065 \\
\hline \multirow{2}{*}{ M8 } & \multirow{2}{*}{1240} & Ham-A & 0.0070 & 0.0054 & 0.0043 & 0.0056 & 0.0047 & 0.0057 \\
\hline & & Ham-B & 0.0056 & 0.0063 & 0.0055 & 0.0063 & 0.0054 & 0.0053 \\
\hline \multirow{2}{*}{ M9 } & \multirow{2}{*}{1378} & Ham-A & 0.1100 & 0.1300 & 0.9400 & 0.1100 & 0.1100 & 0.1300 \\
\hline & & Ham-B & 0.1300 & 0.1200 & 0.1000 & 0.1100 & 0.0910 & 0.0720 \\
\hline \multirow{2}{*}{ M10 } & \multirow{2}{*}{1610} & Ham-A & 0.0077 & 0.0068 & 0.0053 & 0.0059 & 0.0061 & 0.0063 \\
\hline & & Ham-B & 0.0076 & 0.0088 & 0.0074 & 0.0070 & 0.0069 & 0.0063 \\
\hline \multirow{2}{*}{ M11 } & \multirow{2}{*}{2250} & Ham-A & 0.0057 & 0.0075 & 0.0076 & 0.0072 & 0.0070 & 0.0057 \\
\hline & & Ham-B & 0.0076 & 0.0061 & 0.0060 & 0.0067 & 0.0069 & 0.0066 \\
\hline
\end{tabular}

\subsection{S-NPP VIIRS HAM Side Difference}

The S-NPP HAM side difference is also evaluated in this study. Figure 11 shows the trending results of DNB mirror side radiance ratio. Figure 12 shows the HAM side ratio for all studied M bands. The DNB HAM side difference is small. The largest HAM side difference is usually in the edge detectors. It is about $0.35 \%$ in D16 in year 2012. For most of the year, most detector's HAM difference is less than $0.2 \%$.

In 2017, all detectors annual average radiance difference for HAM A to HAM B is: $0.00 \%$ for DNB, $0.22 \%$ for M1, $0.17 \%$ for $\mathrm{M} 2,0.15 \%$ for $\mathrm{M} 3,0.09 \%$ for $\mathrm{M} 4,-0.07 \%$ for $\mathrm{M} 5,0.02 \%$ for $\mathrm{M} 7,0.01 \%$ for $\mathrm{M} 8,1.4 \%$ for $\mathrm{M} 9,0.01 \%$ for M10, and $0.03 \%$ for M11. The difference is small and stable since 2012. The bands M1-M4 have relatively larger difference, comparing with the other $\mathrm{M}$ bands. The maximum differences in some detectors are up to $0.4 \%$, and most of them are lower than $0.2 \%$. The M1, M2 bands results indicates that their HAM A side radiance is slightly higher than the HAM B side radiance by about $0.2 \%$ for the average of all detectors. For M5, M7, M8, M10, and M11, their HAM side difference is very small and stable over all years. 
The yearly trends indicate that each year the HAM side difference has some variation due to the variation of the data. The HAM side difference in 2017 is pretty small comparing with other years. The HAM side difference is stable and not getting larger in the past few years thus the HAM side difference in S-NPP VIIRS is negligible.

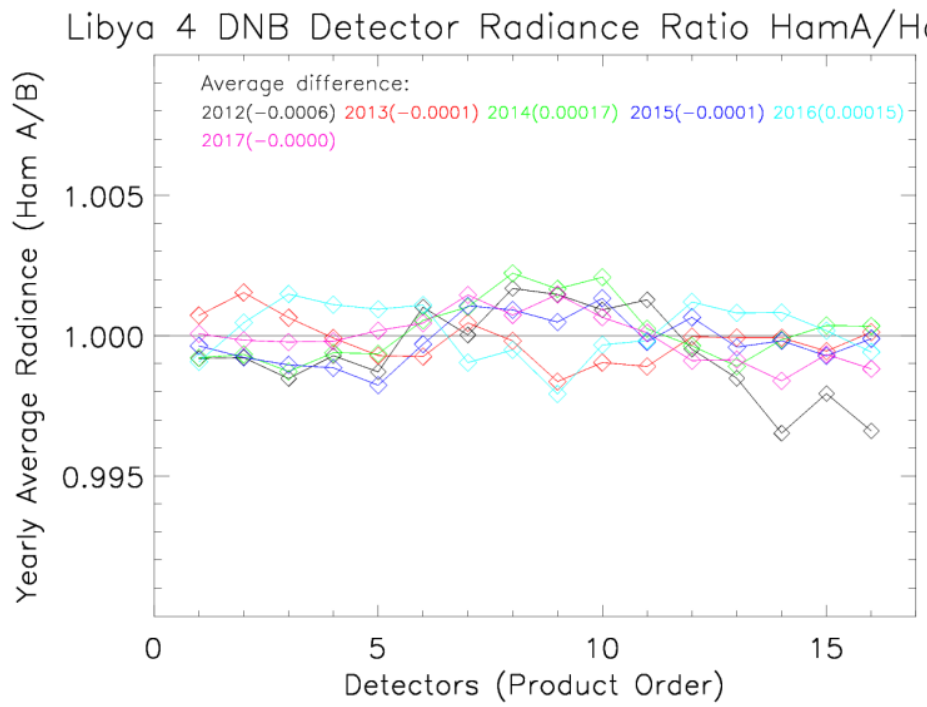

Figure 11. Libya 4 site DNB yearly average HAM side ratio.
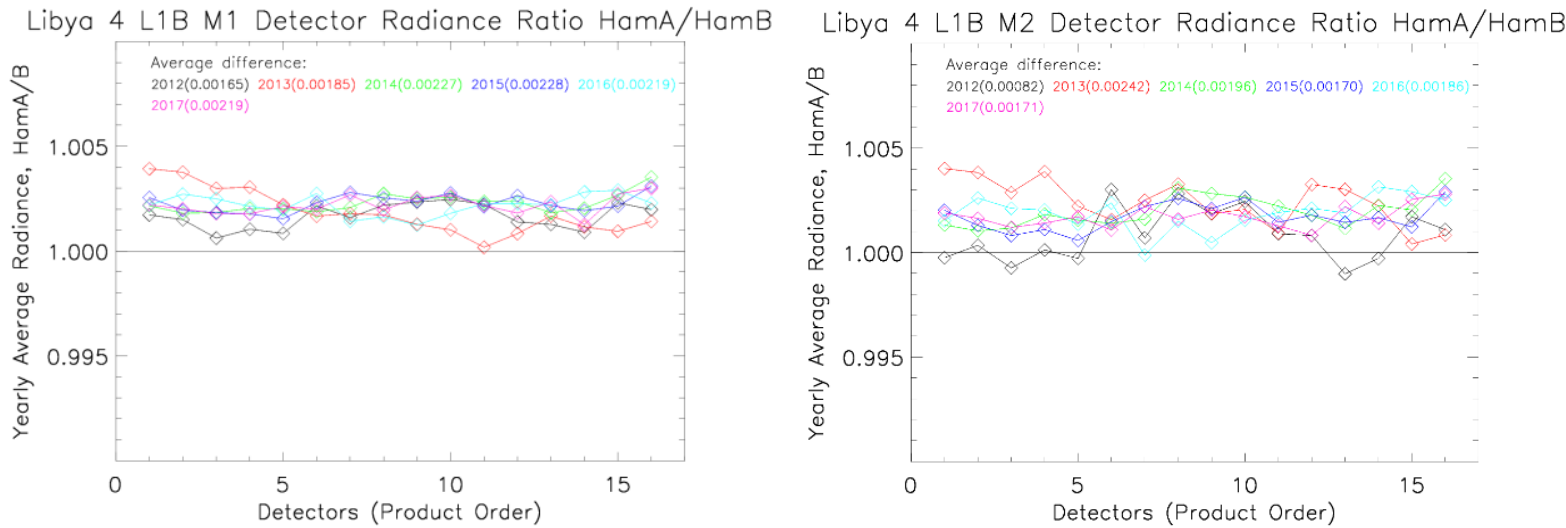

Libya 4 L1B M3 Detector Radiance Ratio HamA/HamB
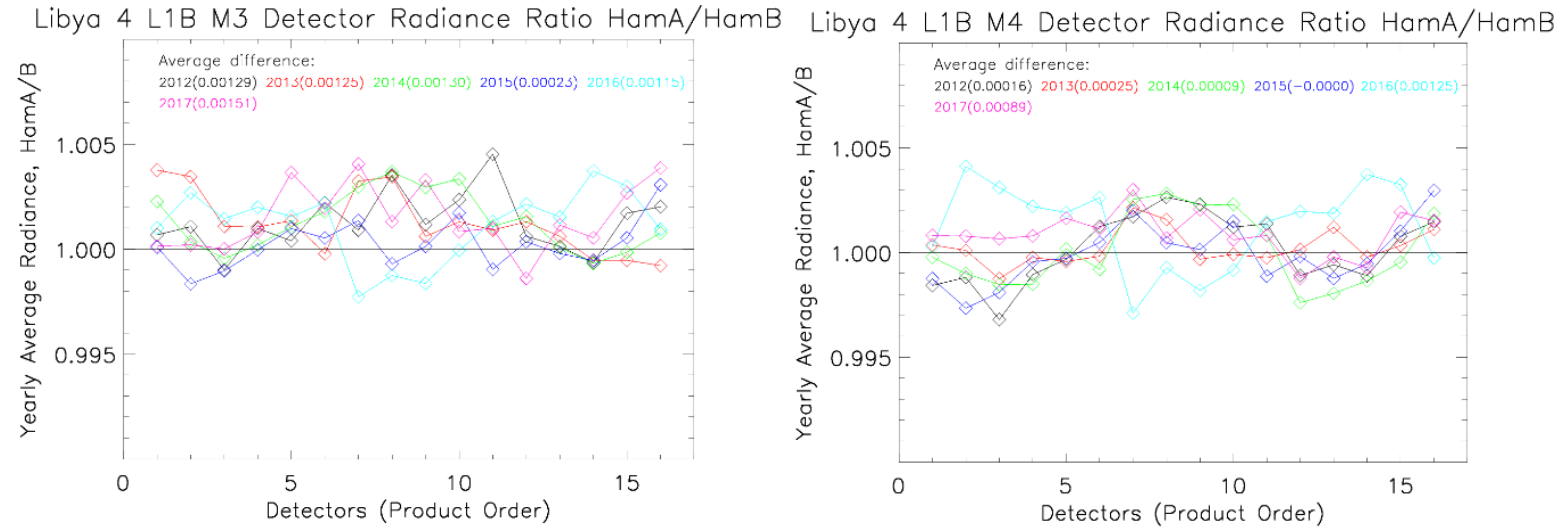

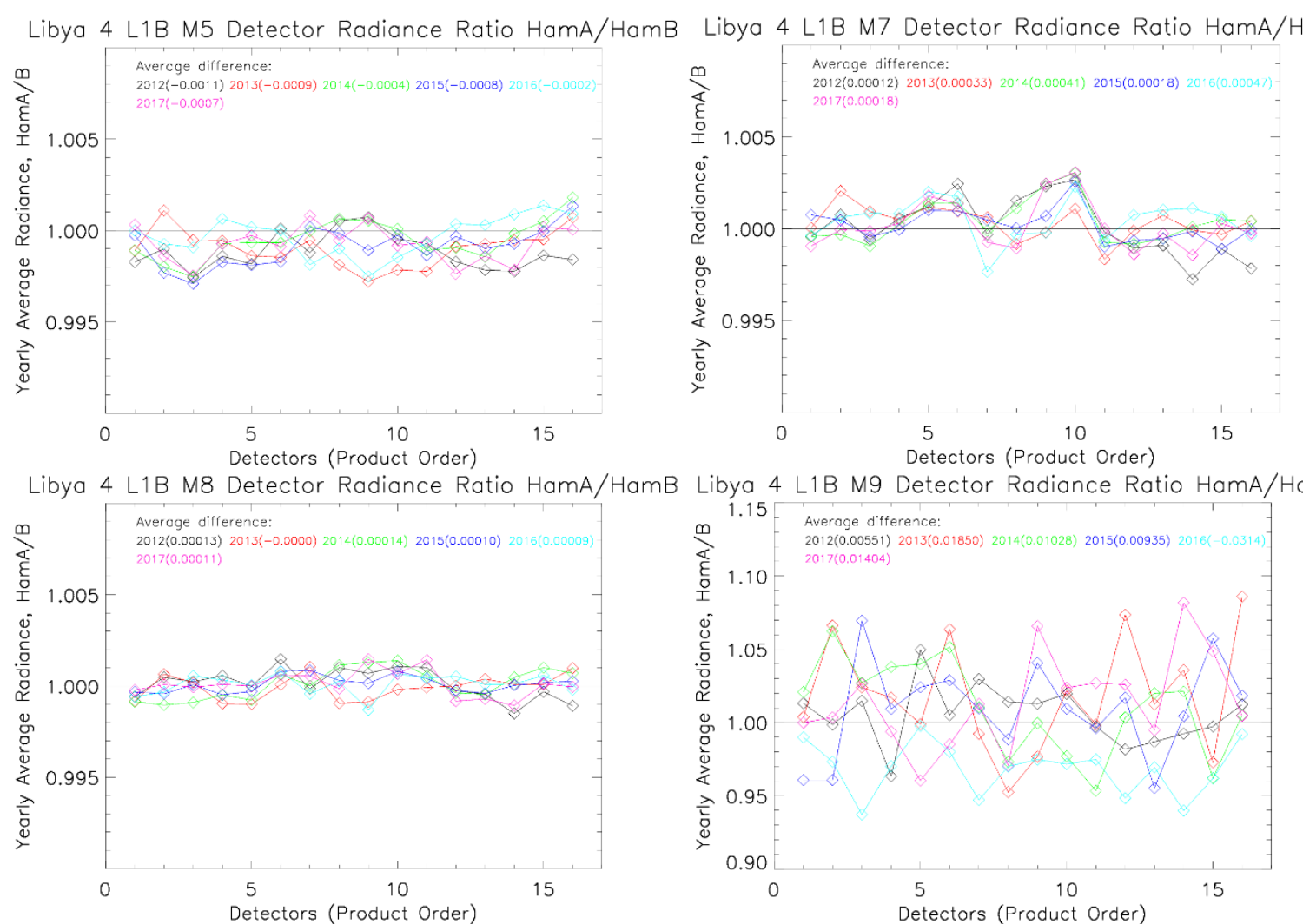

Libya 4 L1B M10 Detector Radiance Ratio HamA/HamB

Libya 4 L1B M11 Detector Radiance Ratio HamA/HamB
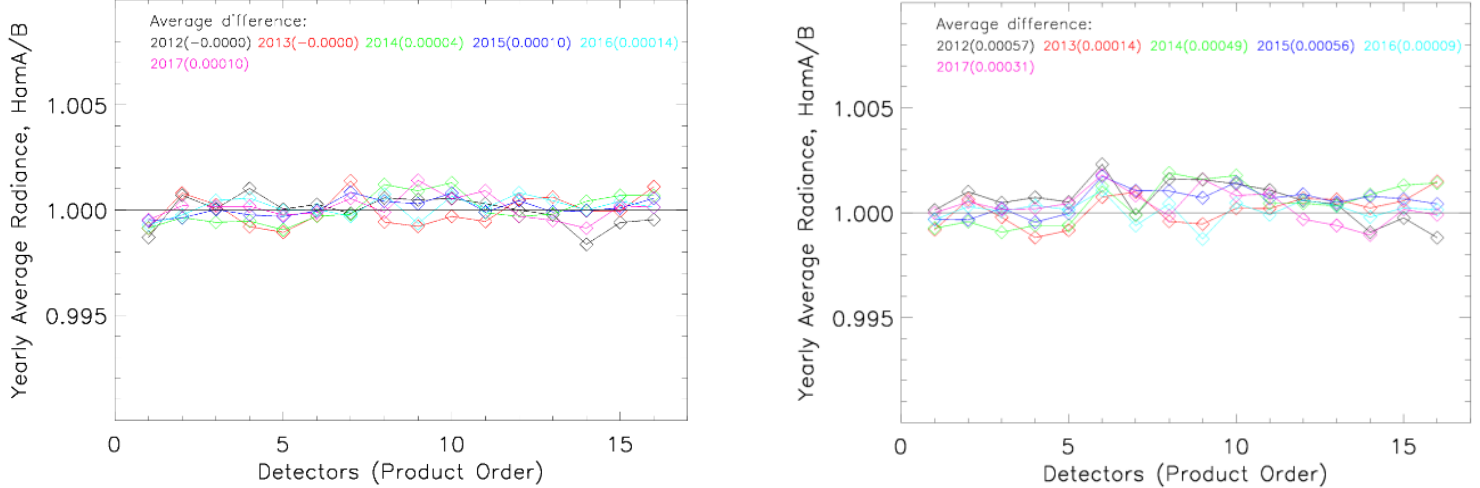

Figure 12. Libya 4 site M bands yearly average HAM side ratio. 


\subsection{Comparing Results with Previous Studies}

The Earth view data is more complex than the onboard calibration data because its noise is mixed with diverse signal sources. Thus Earth view data is suitable to evaluate the overall calibration accuracy and help to find the error sources. The onboard calibration data has no atmospheric influence and is close to spatially uniform, thus it is more suitable to analyze the instrument effects, such as the BRDF influence and other instrument system error or noise sources. A study by Lei et al. using the onboard calibration SD panel data found that the SD BRDF value degraded non-uniformly with time [20]. The research found that differences of up to $3-4 \%$ in solar energy exposure over the VISNIR bands' detector SD footprints likely causes spatially non-uniform degradation of the SD. In our study, the M1-M4 maximum detector difference changes with time and the percentage of change matches well with the Lei et al. [20] study. We believe this non-uniform degradation of the SD leads to an error in the calibration and this is the main cause of the detector difference we see in the Earth view RSB data.

Results from the study on the S-NPP detector Earth view spectral radiance difference from DCC [19] are also compared with our results. DCCs are consistent targets which are cold and bright, and are nearly Lambertian at low solar and view zenith angles. The DCCs reflectance spectrum observed by the sensor contains minimal amount of water vapor and aerosols influence, compared to the observation of ground targets. A DCC study on S-NPP VIIRS SDR from February 2012 to June 2015 indicated that most solar reflective bands' detector differences were less than $1 \%$ comparing with the mean values, except for I3 and M10 bands [19]. The detector differences showed increasing trends for some short-wave bands (M1-M5) and the other bands with longer center wavelengths remain stable. The HAM side difference was insignificant and stable in DCC observations. Those short-wave bands from M1-M4 also had relatively larger HAM side difference. M1 had up to $0.25 \% \pm 0.04 \%$ HAM side difference. In our study, M1 is also the band that has the large detector difference as $1.7 \%$ and its HAM side difference is $0.22 \%$ in 2017 .

The Libya 4 M1 to M11 bands detector differences are very close to the DCC results, except M9 and M10. Scarino et al. [28] showed the SCIAMACHY hyperspectral data for Libya 4 site, DCC site, and other Earth view targets. In Libya 4 desert site, M9 band channel had very low reflectance $(\sim 0.05)$ and also had large influence from atmospheric aerosol while M10 had high reflectance ( $\sim 0.6)$ and also had some influence from atmosphere [28] [figure 1,3]. The DCC reflectance was high in M9 ( 0.6) and low in M10 ( 0.2) [28]. Thus the M10 detector difference was smaller in Libya 4 site $(\sim 0.7 \%)$ than in the DCC study site $(\sim 1.6 \%)$ in 2015 data. The difference in M9 and M10 results are due to the atmosphere influence and the different characteristics of the two targets. We believe the M9 results is more accurate in the DCC study whereas the M10 result is more accurate in our Libya 4 site study due to their high SNR.

In the VIIRS sensor, the HAM is the only optical component with a varying angle of incidence during the scanning hence it is the only optical component which may change the polarization sensitivity during scanning. S-NPP VIIRS polarization sensitivity is wavelength dependent and detector dependent [27]. The polarization sensitivity is higher at a shorter wavelength and in lower detector index [27], which matches with the observation of the detector differences in our Libya 4 study. Currently polarization corrections have not been applied in the S-NPP VIIRS RSB calibration algorithm. We believe that the HAM side difference in S-NPP VIIRS is caused by the polarization effects and may also be scene dependent.

\section{CONCLUSIONS}

The Suomi NPP VIIRS has been operating to collect global data for almost seven years now. In this study, we use S-NPP VIIRS observed Earth radiance from the Libya 4 site to determine the detector-to-detector differences and HAM side differences for the DNB and RSB M bands. The analyses are based on the Libya 4 nadir image radiance data repeated every 16 days from February 2012 to June 2018. To reduce the effect of seasonal variation, Earth-Sun distance correction and solar zenith angle correction are applied to the radiance data. The ratio of individual detector to all detector mean radiance per HAM side are calculated. The yearly averaged detector radiance ratio and HAM side ratio are investigated from 2012 to 2017. The 2017 annual data analysis indicates that the maximum detector differences are $0.77 \%$ for DNB, $1.7 \%$ for $\mathrm{M} 1,1.8 \%$ for $\mathrm{M} 2,1.3 \%$ for $\mathrm{M} 3,1.2 \%$ for M4, and the M5-M11 are all less than $0.8 \%$ except M9. The detectors close to the two edges have the largest differences relative to the center detectors.

The current Earth view data from the Libya 4 site also indicates small mirror side differences in S-NPP VIIRS. It is $0.22 \%$ for M1, $0.17 \%$ for M2, $0.15 \%$ for M3, and the other RSB bands are less than $0.1 \%$ except M6 and M9. It is likely 
due to polarization effects and is scene dependent. In this study, both detector-to-detector differences and HAM side differences are found to be wavelength dependent. The larger differences are in the shorter wavelengths. Our study results have been compared with some previous research, such as Chang et al. DCC research [19] and Lei et al. S-NPP SD BRDF degradation [20]. Due to the low reflectance in M9 at the Libya 4 site, M9 results are not accurate in this study while M10 results are more reliable than that in the DCC research. The other bands' performance is consistent with the previous studies.

Although the SD is expected to accurately characterize detector response in the current onboard calibration algorithm, the uncertainties associated with the time-dependent SD degradation, such as solar exposure time, result in inadequacies in the estimation of each detector's gain. This can cause the detector differences and image striping to increase with time. We believe that the HAM side difference in our study may be caused by the polarization effects related to the HAM characteristics. In the future we will also test more ground sites to see whether these differences are scene dependent.

The procedure for selecting usable scenes and data processing for the detectors trending is a routine task that is doable for other scientists. The long term trending used in this study is helpful for monitoring each detector's performance and the HAM characteristics. Dead detectors or noisy detectors can be identified from these observations if there will be any in the future. Our research results can provide assessment for S-NPP VIIRS performance as well as provide motivation and direction for future algorithm improvement. Our future work will continue to monitor the monthly change for each detector and will also add more ground targets, such as the Dome C and Deep Ocean sites. When the detector differences get large enough to trigger a correction in the algorithm, we can also use this study's method to validate the correction results.

\section{ACKNOWLEDGMENTS}

The SCIAMACHY data source is distributed by the European Space Agency. The authors would like to thank the VCST group internal reviewers for their comments to improve this study. The VCST and MCST colleagues also provided technical assistance in this study.

\section{REFERENCES}

[1] Xiong, X., Butler, J., Chiang, K., Efremova, B., Fulbright, J., Lei, N., McIntire, J., Oudrari, H., Wang, Z., and Wu, A., "Assessment of S-NPP VIIRS On-Orbit Radiometric Calibration and Performance," Remote Sensing, 8(2), 84; doi:10.3390/rs8020084, (2016).

[2] Butler,J., Xiong, X., oudrari, H., Pan, c. , and Gleason, J., "NASA calibration and characterization in the NOESS Preparatory Project (NPP)," IGARSS (2009).

[3] Cao, C., De Luccia, F. J., Xiong, X., Wolfe, R., Weng, F., "Early on-orbit performance of the Visible Infrared Imaging Radiometer Suite onboard the Suomi National Polar-Orbiting Partnership (S-NPP) Satellite," IEEE Transactions on Geoscience and Remote Sensing, 52(2), 1142-1156, doi:10.1109/TGRS.2013.2247768, (2013).

[4] Northrop Grumman Aerospace Systems, "JPSS VIIRS Radiometric Calibration Algorithm Theoretical Basis Document ATBD," Revision C, https://nsidc.org/sites/nsidc.org/files/technical-references/JPSS-ATBD-VIIRS-SDRC.pdf, (2014).

[5] NOAA Technical Report NESDIS 142, "Visible Infrared Imaging Radiometer Suite (VIIRS) VIIRS Sensor Data Record (SDR) User's Guide," Version 1.2, https://www.star.nesdis.noaa.gov/smcd/spb/nsun/snpp/VIIRS/VIIRS_SDR_Users_guide.pdf, (2013).

[6] Lei, N., Xiong, X., and Guenther, B., "Modeling the detector radiometric gains of the Suomi NPP VIIRS reflective solar bands," IEEE Transactions on Geoscience and Remote Sensing, 53(3), 1565-1573, (2015).

[7] Oudrari, H., McIntire, J., Xiong, X., Butler, J., Lee, S., Lei, N., Schwarting, T., and Sun, J., "Prelaunch radiometric characterization and calibration of the S-NPP VIIRS sensor," IEEE Transactions on Geoscience and Remote Sensing, 53(4), (2015).

[8] Barrie, J.D., Fuqua, P.D., Meshishnek, M.J., Ciofalo, M.R., Chu, C.T., Chaney, J.A., Moision R.M., and Graziani, L., "Root cause determination of on-orbit degradation of the VIIRS rotating telescope assembly," Earth Observing Systems XIII, Proceedings of SPIE, San Diego, 8510, (2012). 
[9] Lee, S., Chiang, K., Xiong, X., Sun, C., and Anderson, S., "The S-NPP VIIRS Day-Night Band on-orbit calibration/characterization and current state of SDR products," Remote Sensing, 6, 12427-12446, doi:10.3390/rs61212427, (2014).

[10] Lei, N., Chen, X., and Xiong, X., "Determination of the SNPP VIIRS SDSM screen relative transmittance from both yaw maneuver and regular on-orbit data," IEEE Transactions on Geoscience and Remote Sensing, 54(3), 1390-1398, DOI: 10.1109/TGRS.2015.2480039, (2015).

[11] Barrett, E. C., Brown, K. A., Micallef, A., [Remote Sensing for Hazard Monitoring and Disaster Assessment: Marine and Coastal Applications in the Mediterranean Region], CRC Press. ISBN 9782881248092-CAT\#TF2660, (1991).

[12] Miller, S. D., Lee, T. F., and Fennimore, R. L., "Satellite-based imagery techniques for daytime cloud/snow delineation from MODIS," Journal of Applied Meteorology, Volume 44, pages 987-977, https://doi.org/10.1175/JAM2252.1, (2005).

[13] Wu, A., Xiong, X., Angal, A., and Barnes, W., "Evaluation of detector-to-detector and mirror side differences for Terra MODIS reflective solar bands using simultaneous MISR observations," International Journal of Remote Sensing, 32: 2, 299-312, DOI: 10.1080/01431160903464138, URL: http://dx.doi.org/10.1080/01431160903464138, (2011).

[14] Angal, A., Sun, J., Geng, X., Chu, M., and Xiong, X., “Assessment of the MODIS RSB detector differences using Earth-View targets,” Earth Observing Systems XVIII, Proc. of SPIE, Vol. 8866, 88661T, (2013).

[15] Li, Y., Angal, A., Wu, A., Geng, X., Link, D., Xiong, X., "Calibration improvements in the detector-to-detector differences for the MODIS ocean color bands," Earth Observing Systems XXI, Proc. of SPIE, Vol. 9972, 99721V-1, doi: 10.1117/12.2236920, (2016).

[16] Chang, T., Xiong, X., Angal, A., and Mu, Q., "Assessment of MODIS RSB detector uniformity using deep convective clouds," Journal of Geophysical Research: Atmospheres, 121, 4783-4796, doi:10.1002/2015JD024652, (2016).

[17] Bouali, M., and Ignatov, A., "Adaptive reduction of striping for improved sea surface temperature imagery from Suomi National Polar-Orbiting Partnership (S-NPP) Visible Infrared Imaging Radiometer Suite (VIIRS),” Journal of Atmospheric and Oceanic Technology, Volume 31, page 150-163, (2014).

[18] Wang, Z. and Cao, C., "Assessing the effects of Suomi NPP VIIRS M15/M16 detector radiometric stability and relative spectral response variation on striping," Remote Sensing, 8, 145, doi:10.3390/rs8020145, (2016).

[19] Chang, T., Xiong, X., and Mu, Q., "VIIRS reflective solar band radiometric and stability evaluation using deep convective clouds," IEEE Transactions on Geoscience and Remote Sensing, Volume 54, Issue 12, (2016).

[20] Lei, N., Chen, X., Chang, T., Xiong, X., "Positional dependence of the SNPP VIIRS SD BRDF degradation factor," Proceedings of SPIE Remote Sensing, Sensors, Systems, and Next-Generation Satellites XXI, Vol.10423, doi: 10.1117/12.2277715, (2017).

[21] Wang, M., Liu, X., Tan, Li, Jiang, L, Son, S.H., Shi, W., Rausch, K., and Voss, K., "Impacts of VIIRS SDR performance on ocean color products," Journal of Geophysical Research: Atmospheres, Vol.118, pp.10347-10360, doi:10.1002/jgrd.50793, (2013).

[22] Wang, M., "VIIRS ocean color products", Proc. JPSS Annual Meeting, pp.1-17. [Online]. http://www.star.nesdis.noaa.gov/star/documents/meetings/2015JPSSAnnual/dayTwo/10_Session3_Wang_OC_updat es2.pdf, (2013).

[23] Angal, A., Xiong. X., Choi, T., Chander, G., and Wu, A., "Using the Sonoran and Libyan Desert Test Sites to monitor the temporal stability of reflective solar bands for Landsat 7 ETM+ and Terra MODIS sensors," Journal of Applied Remote Sensing, 4(1), 043525-12, (2010).

[24] Angal, A., Xiong. X., Choi, T., Chander, G., and Wu, A, "Using the Sonoran and Libyan desert test sites to monitor the temporal stability of reflective solar bands for Landsat 7 ETM+ and Terra MODIS sensors," Journal of Applied Remote Sensing, 4(1), 043525-12, (2010).

[25] Wu, A., Xiong, X., Cao, C., and Angal, A., "Monitoring MODIS calibration stability of visible and near-IR bands from observed top-of-atmosphere BRDF-normalized reflectances over Libyan desert and Antarctic surfaces," Earth Observing Systems XIII, Proceedings of SPIE, San Diego, (2008).

[26] Hudson, S.R., Wang, S.G., Brandt, R.E., Grenfell, T.C., and Six, D., "Spectral bidirectional reflectance of Antarctic snow: measurements and parameterization," Journal of Geophysical Research, 111, D018106, (2006).

[27] Luccia, F.D., Guenther, B., Moeller, C., Xiong X., and Wolfe, R., "NPP VIIRS pre-Launch performance and SDR validation,", IEEE International Geoscience and Remote Sensing Symposium (IGARSS), Vancouver, Canada, https://www.slideshare.net/grssieee/1-npp-viirs-prelaunch-performance-and-sdr-validation-igarss-2011pptx, (2011). 
[28] Scarino, B.R., Doelling, D.R., Minnis, P., Gopalan, A., Chee, T., Bhatt, R., Lukashin, C., Haney, C., “A Web-Based Tool for Calculating Spectral Band Difference Adjustment Factors Derived from SCIAMACHY Hyperspectral Data, "IEEE Transactions on Geoscience and Remote Sensing, Vol. 54, Issue 5, 2529-2542, (2016). 